\title{
Ensuring the safety of workers in underground electrical installations - professional risk assessment
}

\author{
Georgeta Buică $^{1 *}$, Anca Elena Antonov ${ }^{1}$, Constantin Beiu ${ }^{1}$, Dragos Pasculescu ${ }^{2}$ and Remus \\ Dobra $^{3}$ \\ ${ }^{1}$ INCDPM „Alexandru Darabont” of Bucharest, Certification Body, 35A Ghencea Blvd, Bucharest, \\ Romania \\ ${ }^{2}$ University of Petrosani, 20 Universitătii st., Petrosani 332006, Hunedoara, Romania, \\ ${ }^{3}$ University "1 Decembrie 1918” Alba-Iulia, Romania
}

\begin{abstract}
Occupational risk assessment is a prevention tool used to manage safety and health at work in the national economy sectors of activity.

Within the operation and maintenance in underground electrical installations, several major risk factors are identified, mainly due to work equipment cumulated with risk factors generated by the work environment and workload.

To highlight the working conditions and the technical requirements of the underground electrical installations, the activity carried out for 50 years was analyzed, taking into account the lifespan of the electrical installations. Also, the events and accidents at work, the assessments of the risk in the workplace was analysed and represents a synthesis of research studies carried out so far.

The research highlights the role of safety measures aimed to ensure the safety and health of workers working in underground electrical installations, mainly about work equipment and the means of work against electrocution to efficiently manage occupational risks and reduce workplace accidents and occupational disease, as well as technical events in electrical installations.
\end{abstract}

\section{Introduction}

In the last years in the urban areas, the aim was to replace the overhead electric power distribution lines with the underground power lines (UPL). This objective of environmental and safety and health at work management eliminates the "aesthetic pollution" and some risk of accidents such as falling from heights, reduce the emission of electromagnetic fields, noise, and "aesthetic pollution" and "psychological pollution" generated by fear of proximity from electrical systems and physical effects, but involves difficult and costly mounting and maintenance.

\footnotetext{
* Corresponding author: georgiana_buica@yahoo.com
} 
From the analysis of national statistical data regarding the events and accidents at work ait is noticed although the feeling of fear caused by electrical installations on the human factor is reduced for underground electric lines, at the national level are registered and publicizes serious accidents resulting in fatalities due to unauthorized work near these lines, access and interventions of unauthorized persons and theft of electricity and electrical equipment components.

The diagnosis of the activity carried out by the operating and maintenance personnel in the electrical installations, respectively the UPL, the analysis and the evaluation of the professional risks was carried out within the works of evaluation of the level of risk of accident and occupational disease that took place during the years $2000-2018$, realized at a part of the national energy companies and following the studies carried out in order to evaluate the working conditions of the installations during the last 50 years (11)

\section{Minimum technical and safety requirements related the work places in underground power cables}

The diagnosis of activity performed by operating and maintenance personnel was made by analysing the components of the work system and the technical-economic demands, in conjunction with the provisions of the legislation on safety and health at work and the technical regulations issued by the national authorities in the energy field.

According to GD no.1091/2006, workplaces that use electrical installations and implicitly UPL must be arranged so that there is no danger of fire, explosion and workers are protected against electric shock by direct contact, indirect contact and step voltage. [1, 2]. The technical and economical requirements provide that cable routes should be chosen so that to avoid possible areas of fire or areas where the integrity of the cable is jeopardized by mechanical damage by corrosive agents, laying in water, vibration, overheating or arcing caused by other cables. [3]

However, technical regulations provide requirements for including them in the environment and requirements to ensure access for assemble, maintenance and intervention in case of fire.

\section{Study on the activities carried out by operating and maintenance for underground power lines}

The activity consists in a combination of tasks performed with certain work equipment in a work environment (underground or over ground) with specific authority and quality in a certain organizational structure. [4]

The object of the activity, is operation, interventions at faults and damages, repairs and inspections of underground power lines.

A big part of activities consist of accidental intervention in case of emergencies, and also as a result of excavations carried out in numerous actions on cable routing during construction, or other works carried out by general citizens.

Means of production / work equipment used in this activity according to work task are:

- Work equipment (tool kits, tool kits for bushing; lamp flame or burner with cylinder gas, tools and equipment for digging (pick hammer, drill, mini-excavator) means of communication, equipment for identifying the cable and defects on cable, measuring the insulation resistance, tents for bad weather protection, means of lighting; devices for cutting cables, systems for supporting excavation; bridges for crossing over pits and ditches, pumps for water seepage; sensors for gas, etc.) tools and safety equipment, specific equipment for fault detection. 
- Materials and spare parts. [5].

From the data collected in the research studies carried out, the technical revision works represent approx. 30\%, current revision works $40 \%$ and accidental interventions and operates approximately $30 \%$. [5, 11-16].

There was a tendency to increase the weight of interventions and accidental work and decrease of revision work the technical aspect directly related to the level of the equipment and functionality of the energy equipment and installations, of the degree of their modernization. The increase of the intervention works, and the accidental works are due to some actions/works performed on the cable route during the numerous actions of constructions, arrangements or other works performed by the citizens or construction companies.

The means of production/work equipment used in carrying out the activity according to the workload are the low voltage and high voltage underground power lines (rated voltage $0.4 \mathrm{kV} \div 110 \mathrm{kV}$ ), work equipment (e.g. tool kits; sleeve kits) ; lamps with open flame or burner with bottle and gas; tools, tools and digging equipment (pick hammer, drill, miniexcavator); media; equipment for detecting defects in the cable and identifying the cable, measuring the insulation resistance; protection tents at weathering; lighting means; cable cutting devices; excavation support systems; pits for pits and ditches, pumps for removing water seepage; gas detectors), protective equipment and equipment, specific equipment for fault detection and materials and spare parts.

Electrical installations, depending on their rated voltage, have in composition the same types of electrical equipment, based on some standard operating diagrams, diagrams that may have certain particularities depending on the role in the electrical power system [7]. Analysis and diagnosis of this equipment have revealed and drawn some conclusions on the role, status, technical deficiencies of equipment and protection devices through the interaction of the four elements that constitute the system work.

In recent years some of the work equipment, especially the cables, have been replaced, thus eliminating some of the risks (electrical, thermal, fire, explosion), but many work equipment, mainly low voltage ones from the transformer stations and the supply points are in the last period of guaranteeing the reliability which can have as a consequence the increase of the probability of occurrence of the defects and, as such, the increase of the level of risk.

Risks of injury identified are mechanical, electrical, chemical, and thermal and are dependent of electrical installations, work equipment and tools used and may cause specific risk effect of each risk or multiple effects, when the action of several risks is cumulated.

The largest share are for risks determined by electric shock from direct contact (handling the energized cables, at unraveling cables, accidental contact with the remaining energized elements to accidental break of overhead lines existing in work area as a result of wrong maneuvers in substations and indirect contact (accidental damage of insulation of the cables), step voltage (accidental earthing in the vicinity of intervention) and burns caused by arc flashes. For these reasons, the maximum foreseeable consequences in the event of an accident, are in the higher grades of severity scale, death and disability (risk level 6 and 7).

The possibility of exposure to thermal effects are recorded not only during the execution of works in the proximity of energized electrical installations under voltage, utilities (e.g. gas, lighting, urban electrical traction) but also merely present in potentially harmful zones.

The risks of mechanical injury identified are depending on the type of task, the highest share have risks due to digging ditches located on the vehicles roads and pedestrians (impact by vehicles during digging in the working area or by driving the car on public roads, striking by the boom of the excavator during the excavation, crumbling banks of the pit / trench in the work area during the work due to unsporting the banks (vibration, car access near the work area, etc.); projection of particles in the stripping of concrete or 
asphalt; rocks driven by wheels of auto transportation; falling objects, materials from transportation vehicles in the vicinity of the work area or disposed by homeowners; oil jet from accidental breakage of hydraulic system of the excavator due to inadequate pressure hoses).

Theft of electricity (by changing the electrical diagrams of electrical installations) and materials/components, parts of electrical installations (copper, iron, aluminium) expose the operating/maintenance workers to a risk of electric shock and the thermal and mechanical risks.

The risks are amplified by the presence of water and humidity (due to condensation, infiltration, and flood) of galleries and cable canals.

By analyzing work task, it was found that electricians are exposed to physical factor risk generated by adverse climatic conditions (high temperatures in the summer and low temperatures in the winter, precipitation, winds) during the work above the ground and risk factors generated by working conditions in underground (humidity, air flows, inadequate lighting).

The work performed by operating/maintenance workers is difficult and involve a high degree of training, responsibility and neuro-psychic stress.

In carrying out these duties, the workers are permanently mentally stressed determined by the compulsory execution under particular conditions (moisture, extreme temperatures, and airflows) of some activities in a predetermined time (permanent pressure of time to be put into service the power line).

Digging and emptying the pits implies an increased level of physical demand, reaching up to overburden, in relation to the actual conditions from the respective work. The manual support of the cables also requires large physical efforts, with extended static components.

On the other hand, to correct the defects on the cables, it is necessary professional gesture that requires precision, motor coordination and oculomotor.

Digging and emptying the pits implies an increased level of physical demand, reaching up to overburden, about the actual conditions from their work. The manual support of the cables also requires significant physical efforts, with extended static components.

On the other hand, to correct the defects on the cables, it is a necessary professional gesture that requires precision, motor coordination and oculomotor.

From the analysis of job descriptions and the results of studies, was found that professional requirements, involving an increased professional effort and physical and mental stress, lead to psychosocial risk factors that may influence in time the weakening of worker's body.

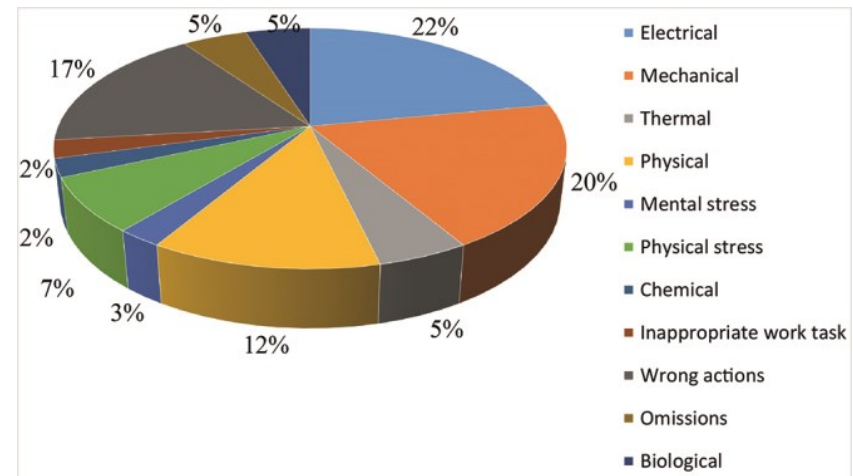

Fig 1. Share of the identified risk factors in electrical installations (UGL - 0.4,-110 kV) $[7,8,9]$ 
Fig.1 presented the share of risk factors identified for UPL and stated that the electrical risk factors have the highest percentage of $22 \%$, followed by the mechanical risk factors with a percentage of $19 \%$. Fig. 3 shows the weight of the risk factors identified for fault detection.

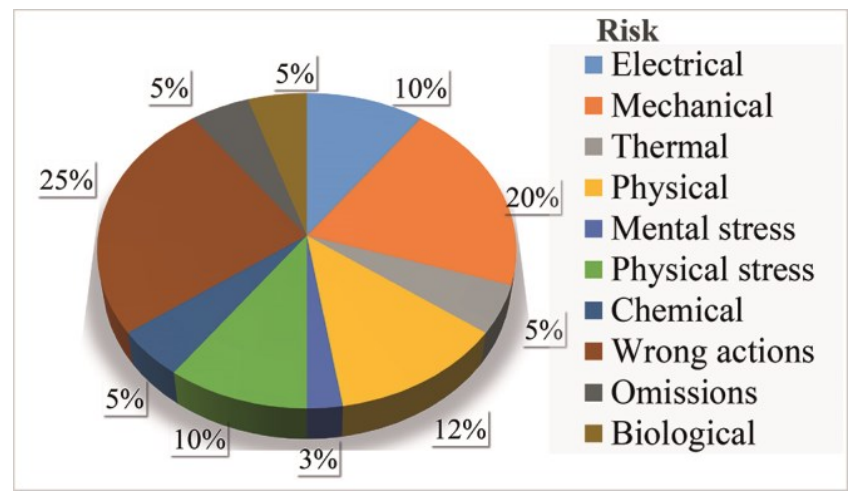

Fig. 2. Share of identified risk factors - fault detection [7].

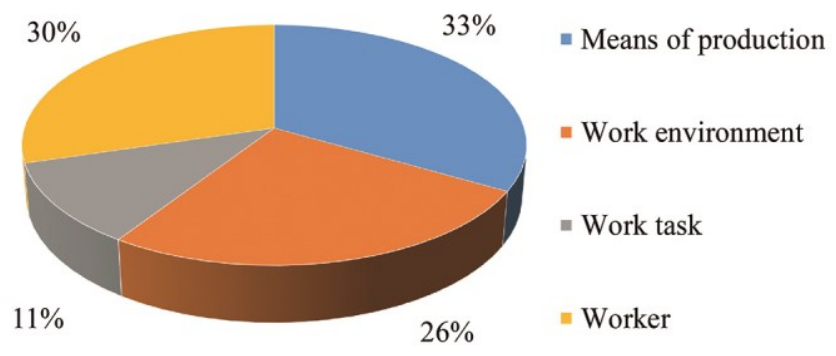

Fig. 3. The distribution of risk factors based on components of work components

From the graphical representation of the distribution of risk factors on work system components shown in Fig. 3, follows that the most harmful situations with potential risks of injury are those given by means of production/work equipment in use with a percentage of $33 \%$ and worker with a percentage of $30 \%[6,7,8,9]$.

Studies on of operating/maintenance underground power lines workers outline the occupational risks on health of workers. Musculoskeletal disorders (36.1\%) and respiratory diseases $(26.9 \%)$ had the most significant weight, followed by the digestive disease with a weight of $17.86 \%$ and cardiovascular with $17.04 \%[6,7,8,9]$.

It was also found that for the operating / maintenance of underground power lines workers with experience and over 51 years the overall morbidity is higher, the cardiovascular diseases being on first place $[6,7,8,9]$.

Fig. 4 present the weight of the diseases registered in the operation and maintenance UPL personnel $[6,7,8,9]$. 


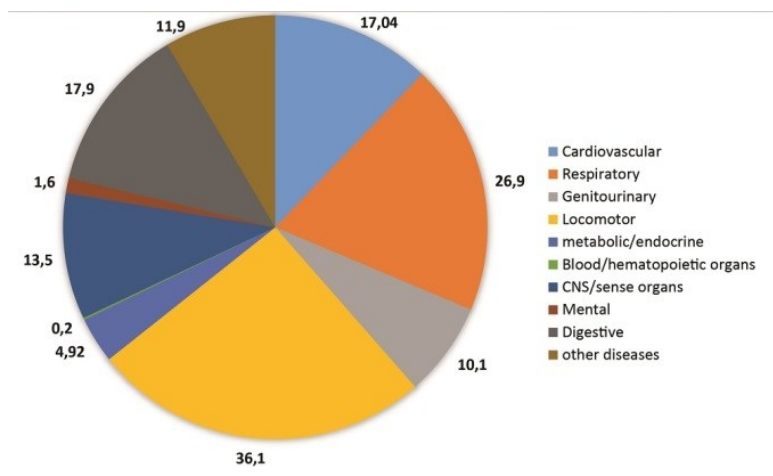

Fig4. Share of illnesses recorded in the operation / maintenance UPL personnel

Regarding the personnel performing fault detection work, was observed that the most common disease is the locomotor disorders, reported in $27 \%$ of the workers, and with close percentages, in all age groups. As a frequency, cardiovascular diseases follow $(21.71 \%)$, but for electricians over 51 years, they appear in the first place, with an impressive weight: $53.3 \%$. Some of these diseases can be multifactorial concerning professional risk factors $[6$, $7,8,9]$.

Identifying, analyzing and assessing the risk of injury and occupational disease arising from the work system elements are the essential tools of risk management, to manage these data to reduce and eliminate the risks by technical and organizational measures [10].

\section{Conclusion}

The study aimed to diagnose the activity carried out in underground powerlines, analyzing and evaluating occupational risks associated, in terms of operating history, maintenance, including the situation arising after the occurrence of events involving workplace accidents.

The results aims to support Romanian employers to guarantee a better level of safety and health of workers and to improve the working environment in underground electrical installations and power distribution lines in order to ensure a more efficient management of occupational risks in the activities of national economic sectors.

\section{References}

1. GD no.1146 (2006) Available on https://osha.europa.eu/fop/romania/ro/legislation/hotarare 114630 august 2006.shtml

2. GD no.1091 (2006) Available on https://www.ilo.org/wcmsp5/groups/public/---ed protect/---protrav/--ilo_aids/documents/legaldocument/wcms 400217.pdf

3. ANRE, NTE 007/08/00 (2008). Available on https://www.anre.ro download/ ORDIN_38_NTE_007_Normativ\%20(2).pdf

4. Standard SR EN ISO 10075-2 (2000)

5. INCDPM, Technical expertise on the assessment of working conditions of electrical installations for SC Electrica SA, between 1969-2001 required to establish group I work conditions, (2010)

6. Dobra R., Buica G, Pasculescu D, Leba M, Proceedings of the Recent Advances in Industrial and Manufacturing Technologies, WSEAS International Conference, Athena, Greece, 5, 58-63, (2013)

7. Buică G., Contributions of diagnostic methods of safty and health at work in electrical installations, Universitas, Petroşani, 70 - 79, (2010) 
8. Buica G, Antonov A, Beiu C, Pasculescu D, Dobra R, Proceedings of the „Trends in New Industrial Revolution, MSE, 121, (2017)

9. Antonov A., Buica G., Beiu C, EEMJ, 13 (6), 1361-1364 (2014)

10. INCDPM, First class of WAHJ ((workers in arduous or hazardous jobs) established according to Romanian legislation), (2009)

11. Evi BatraMaria G Ioannides Maria G Ioannides, J occupational safety and ergonomics 3 (7), 285-307 (2001)

12. Gourbiere, E., Corbut, J.P., \& Bazin,Y., Annals of the New York Academy of Sciences, (720), 259-271 (1994).

13. Grube, B.J., Heimbach, D.M., Engrav, L.H., \& Copass, M.K., Journal of Trauma, 30(3), 254258, (1990)

14. Hammond, J.S., \& Ward, C.G., Southern Medical Journal, 81(11), 1351-1352, (1988).

15. Harvey, P.L., Driscoll, T.R., Frommer, M.S., \& Harrison, J.E., Scandinavian Journal of Work, Environment and Health, 18(5), 293-297, (1992)

16. Health and Safety Executive, Occasional Paper Series, OP6, London, UK: HMSO (1983). 